\title{
The impact of the dimensions of environmental performance on firm performance in travel and tourism industry
}

\begin{abstract}
This study investigates the impact of the aggregate and individual dimensions of environmental performance (EP) on financial performance (FP), based on a dataset covering the travel and tourism industry (airlines, casinos, hotels, and restaurants) across different economic regions over the period 2003-2014. The results reveal that EP positively affects the FP in the hotel industry when aggregate EP is used. When individual dimensions of EP are considered, resource reduction is found to positively (negatively) affect the performance in the hotel (airline) industry, while product innovation positively affects the performance in the restaurant industry. Hence, the trade-off effect seems to be dominant in the airline industry, and the 'heterogeneous resources and reputation-building' hypothesis is evident in both the hotel and restaurant industries. In addition, in general, the findings support the positive moderating effect of slack resources on the relationship between the individual dimensions of $\mathrm{EP}$ and FP in the travel and tourism industry, and, hence, are supportive of the slack resources hypothesis. These effects, however, vary depending on the travel and tourism industry under investigation.
\end{abstract}

Keyword: Environmental performance; Financial performance; Slack resources; Panel regression; Travel and tourism industry 